\title{
Effect of N-R transitions during partial reinforcement pretraining on subsequent resistance to discrimination
}

\author{
STEVEN J. HAGGBLOOM \\ Arkansas State University, State University, Arkansas 72467
}

\begin{abstract}
Three groups of 12 rats received 25 pretraining trials to each future discriminandum employed in a subsequent differential brightness conditioning problem. Groups NR and RN received partial reinforcement (PRF) pretraining either with or without, respectively, transitions from nonrewarded to rewarded trials (N-R transitions). Group CRF received consistent reinforcement during pretraining. A fourth group $(n=12)$, Group NP, received no pretraining. During discrimination learning, one-half of the rats in each group received all their daily S+ trials preceding their daily $\mathrm{S}-$ trials $(+-$ sequence); the remainder of the rats received an intermixed sequence of trials to $\mathrm{S}+$ and $\mathrm{S}-(+-+$ sequence). Discrimination learning was faster under the +- sequence than under the +-+ condition, and discrimination learning was retarded in Group NR relative to the other three groups, which did not differ from one another, under both the +- and +-+ discrimination sequence conditions. The results are discussed with reference to previous experiments demonstrating $N-R$ transition effects on discrimination learning, a theoretical extension of sequential theory to discrimination learning, and the effects of nondifferential reinforcement prior to discrimination learning on learned irrelevance.
\end{abstract}

Discrimination learning is retarded in groups given an intermixed sequence of trials to the positive $(\mathrm{S}+)$ and negative (S-) stimuli, which contains transitions from nonrewarded trials in S- to rewarded trials in $\mathrm{S}+$ (N-R transitions), relative to groups given all of their daily $\mathrm{S}+$ trials preceding their daily $\mathrm{S}-$ trials (Haggbloom, 1978; Haggbloom \& Tillman, 1980). Partial reinforcement (PRF) administered within S+ also retards discrimination learning, but only if the S+ PRF schedule contains N-R transitions (Haggbloom, 1980a, 1980b, 1980c, 1981b; McHose \& Blackwell, (1975). These effects of N-R transitions on discrimination learning are due primarily to retarded extinction of responding to $S-$, a behavior termed resistance to discrimination (Haggbloom, 1980b).

The effect of N-R transitions on resistance to discrimination parallels the effect of that variable on resistance to extinction following conventional PRF (e.g., Capaldi, 1966). And both effects appear to be due to the behavioral control acquired by $S N$, the memory of nonreward. In discrimination learning, $\mathrm{S}^{\mathrm{N}}$ enters into a stimulus compound with the nominally relevant discriminanda (e.g., brightness cues) and can control behavior in a way that either interferes with or complements the control exercised by

This experiment was supported in part by a grant from Arkansas State University and by NIMH Grant 1 R03 MH33349-01 to the author. The author wishes to thank Professor John K. Beadles for the use of laboratory space in the Department of Biology. Requests for reprints should be addressed to the author, Department of Psychology, Arkansas State University, P.O. Box 2127, State University, Arkansas 72467. those cues (Capaldi, Berg, \& Morris, 1975; Haggbloom, 1978; Haggbloom \& Tillman, 1980). Given a trial sequence that contains $N-R$ transitions, responding is conditioned to $\mathrm{S}^{\mathrm{N}}$ so that on subsequent trials $\mathrm{S}^{\mathrm{N}}$ in compound with $\mathbf{S}$ - elicits faster running than would be elicited by the $S$ - cue alone. Indeed, rewardproduced cues like $\mathrm{S}^{\mathrm{N}}$ not only are an inherent feature of discrimination learning, but they also represent a salient source of stimulus control for the rat, which, under some schedule conditions, can overshadow (Haggbloom \& Tillman, 1980) or block (Haggbloom, 1981a) the acquisition of control by cues such as brightness. Thus, a complete understanding of discrimination learning will require specification of the way in which reward-produced cues and other cues jointly control behavior.

The purpose of the present experiment was to extend our knowledge of sequential effects-specifically, N-R transitions-on resistance to discrimination to include the effects of PRF pretraining. Groups given PRF nondifferentially paired with two cues subsequently employed as relevant discriminanda, or to either of the two cues or a neutral cue alone, show greater resistance to discrimination than groups given consistent reinforcement (CRF) pretraining or no pretraining (Amsel \& Ward, 1965; Galbraith, 1973; Mandler \& Goldberg, 1973; Purdy \& Cross, 1979).

The effects of PRF pretraining appear to be insensitive to whether the pretraining trials are administered to a neutral stimulus or to one or both of the future discriminanda (e.g., Galbraith, 1973). The 
present experiment employed nondifferential pretraining to both future discriminanda (a black vs. a white runway). During the pretraining phase, Group NR received a PRF schedule that contained N-R transitions, Group RN received the same percentage of reinforcement on a schedule that did not contain N-R transitions, Group CRF received reinforcement on all pretraining trials, and, finally, Group NP received no pretraining. In Phase 2, all groups were trained on a successive differential brightness conditioning problem. One-half of the rats in each group received an intermixed sequence of daily $\mathrm{S}+$ and $\mathrm{S}-$ trials (+- + sequence); the remainder of the rats in each group received all their daily $S+$ trials preceding their daily $S-$ trials $(+-$ sequence).

\section{METHOD}

\section{Subjects}

The subjects were 48 male rats, 90 days old at the start of the experiment, bred in the laboratory from Holtzman stock.

\section{Apparatus}

The apparatus consisted of two parallel straight alleys, $105 \mathrm{~cm}$ long $\times 9 \mathrm{~cm}$ high and wide. The walls and floor of one alley were painted white, and the walls and floor of the other alley were painted black. The last $25 \mathrm{~cm}$ of each alley constituted a goalbox separated from the rest of the alley by a manually operated guillotine door. The doors and goalboxes were painted the same color as the alley in which they were located. Each goalbox contained an unpainted wooden goal cup. A gray startbox, $9 \mathrm{~cm}$ high and wide $\times 25 \mathrm{~cm}$ long, could be aligned to permit entry into one alley or the other. The startbox had a gray, manually operated guillotine door. Start times were recorded from the opening of the startbox door, which triggered a .01-sec clock, to a point $30 \mathrm{~cm}$ into the alley. Run and goal times were recorded over the next 40 and $30 \mathrm{~cm}$, respectively. The of fset of the first clock and the operation of the run and goal clocks were controlled by photoelectric circuitry.

\section{Procedure}

All rats were housed individually and had access to water at ail times. Two weeks before the start of experimental training, and continuing throughout the experiment, each rat's food intake was restricted to $12 \mathrm{~g}$ per day. On each of 3 days before the start of training, the rats were handled in squads of four for $4 \mathrm{~min}$ per squad. Also on those days, each rat received 1045 -mg Noyes food pellets placed in a small dish in its home cage.

Pretraining began on Day 15 of deprivation and continued for 12 days, with each rat in Groups NR, RN, and CRF receiving one reinforced trial to the future $S+$ on Day 1 , a reinforced trial to both cues on Day 2, and thereafter five trials per day. For half of the rats in each group, all pretraining trials occurred in the black runway on odd-numbered days and in the white runway on even-numbered days. This was reversed for the other half of the rats in each group. The sequences of rewarded $(R)$ and nonrewarded (N) trials experienced by Group NR over Pretraining Days 3-10 were: RRNRR, RRNNR, RNNNR, RNNRR, RNNNR, RRNNR, RRNRR, RRNNR, RNNRR, RRNNR. Group RN received the same number of $R$ and $N$ trials each day as Group NR, with all daily $R$ trials preceding daily $N$ trials. Group CRF received reinforcement on all pretraining trials. Group NP received no experimental treatment during the pretraining phase.

In the discrimination phase, which immediately followed pretraining and lasted 12 days, Group NP began training and all four groups were trained on a successive differential brightness conditioning problem with three $S+$ and three $S-$ trials given each day. One-half of the rats in each group received all their daily $\mathbf{S}+$ trials preceding their daily $\mathbf{S}-$ trials. The remaining rats in each group received the following three sequences of $S+$ and $S-$ trials recursively over blocks of 3 days: $S+S+S-S-S+S-$, $\mathbf{S}+\mathbf{S}-\mathbf{S}+\mathbf{S}-\mathbf{S}+\mathbf{S}-, \mathbf{S}+\mathbf{S}+\mathbf{S}-\mathbf{S}-\mathbf{S}-\mathbf{S}+$. The black alley was $\mathbf{S}+$ and the white alley was $S-$ for half of the rats in each group. These conditions were reversed for the remainder of the rats in each group.

On $R$ trials in both phases, the rats were removed from the goalbox after the times had been recorded (after approximately $10 \mathrm{sec}$ ) unless the reward had not yet been consumed. Reinforcement consisted of $1045-\mathrm{mg}$ Noyes pellets. On $\mathrm{N}$ trials, the rats were confined to the goalbox for $20 \mathrm{sec}$. A trial was begun by placing a rat in the startbox and opening the startbox door after approximately $3 \mathrm{sec}$, regardless of the rat's orientation. The rats were run in squads of three (Phase 1) or four (Phase 2) containing one rat from each pretraining schedule condition. The order in which trials were administered within a squad varied randomly from day to day, while the order of successive squads was held constant across days. The intertrial interval was 3-4 min. A maximum time of $30 \mathrm{sec}$ was allowed in each section of the alley. If $30 \mathrm{sec}$ was exceeded in any alley section, the additional time was added to the time score of the next section forward. If the rat did not enter the goalbox within $90 \mathrm{sec}$, it was placed in the goalbox.

\section{RESULTS}

All time scores were converted to speeds in $\mathrm{cm} / \mathrm{sec}$. Only total speeds, which were representative of responding in each alley section, are reported here. There was little difference among the three pretraining schedule conditions by the end of pretraining (mean speeds on the last pretraining day of 72.48 , 63.02 , and $68.74 \mathrm{~cm} / \mathrm{sec}$ for the $\mathrm{NR}, \mathrm{RN}$, and $\mathrm{CRF}$ conditions, respectively). A pretraining schedule (3) $\times$ brightness (2) $\times$ trials (5) between-within analysis of variance (ANOVA) applied to speeds on the last pretraining day yielded $F(2,30)=1.85$ for the pretraining schedule main effect. There were no significant interactions with pretraining schedule [largest $F(8,120)$ $=1.56$ for the trials $\times$ pretraining schedule interaction].

As in previous experiments (e.g., Haggbloom, $1980 \mathrm{~b}, 1980 \mathrm{c}, 1981 \mathrm{~b}$ ), differences in resistance to discrimination as a function of sequential variables were manifested primarily in S- behavior; there were no differences among groups in $\mathrm{S}+$ as a function of pretraining schedule, but groups given the +-+ discrimination trial sequence tended to run slightly slower in $\mathrm{S}+$ than groups given the +- sequence (data for $\mathrm{S}+$ not shown). Figure 1 shows the mean speed of each group in blocks of $2 \mathrm{~S}$ - days for the +- (left panel) and +-+ (right panel) discrimination trial sequence conditions in the discrimination phase.

As can be seen in Figure 1, S- speeds were somewhat slower in the +- condition than in the +-+ condition, but the pattern of results due to pretraining schedule was essentially the same in the two discrimination schedule conditions. In both discrimination schedule conditions, Group NR showed con- 


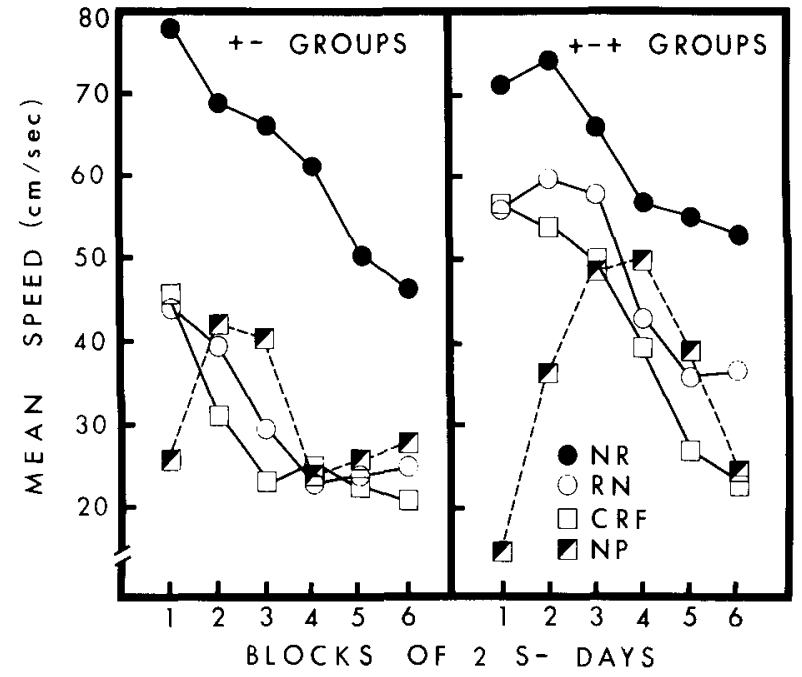

Figure 1. Mean speed in $S-$ for each group during the discrimination phase in blocks of 2 days in the + - (left panel) and +-+ (right panel) discrimination trial sequence conditions.

siderable resistance to discrimination relative to Groups RN, CRF, and NP, which responded essentially alike.

An ANOVA was applied to speeds on the last half of the discrimination phase, with pretraining schedule (4), discrimination trial sequence (2), and brightness (2) as between-subjects factors and trials (3), days (6), and discriminanda (2) as within-subjects factors. The better discriminative performance under the +- discrimination trial sequence than under the +-+ sequence was reflected in a significant discriminanda $x$ discriminanda trial sequence interaction $[F(1,32)=39.89, p<.001]$. Differences in $\mathrm{S}-$ speeds due to pretraining schedule contributed to a significant pretraining schedule $\times$ discriminanda interaction $[F(3,32)=8.76, p<.001]$. Consistent with the observation that the pretraining schedule effects were the same for the two discrimination sequence conditions, the pretraining schedule $x$ discrimination trial sequence $\times$ discriminanda interaction was not significant $[F(3,32)=1.87]$.

Simple effects of discriminanda for each pretraining schedule condition within both discrimination trial sequence conditions showed that $S-$ speeds were reliably slower than $S+$ speeds in each of the eight subgroups [smallest $F(1,32)=21.11, p<.001$, for Pretraining Schedule NR and Discrimination Trial Sequence +-+ ]. Simple effects of discrimination trial sequence at $\mathrm{S}+$ and $\mathrm{S}-$ showed that groups given the +- sequence ran faster in $S+[F(1,56)=$ $18.42, p<.001]$ and slower in $S-[F(1,56)=7.61$, $p<.01]$ than groups given the +-+ sequence. Simple effects of pretraining schedule at S+ and Sshowed that there were differences among groups in $\mathrm{S}-$ due to pretraining schedule $[\mathrm{F}(3,56)=15.36$, $\mathrm{p}<.001]$ but not in $\mathrm{S}+(\mathrm{F}<1)$. Newman-Keuls tests showed that, within each discrimination sequence condition, Group N-R ran faster than each of the remaining three groups (all ps $<.01$ ). No other differences among groups within either the +- or +-+ conditions were reliable.

\section{DISCUSSION}

The present experiment demonstrated that resistance to discrimination following PRF pretraining is a function of N-R transitions. This finding is consistent with the results of previous experiments showing that $\mathrm{N}-\mathrm{R}$ transitions retard extinction of responding to $S-$ when they occur on S- to S+ trial transitions (Haggbloom, 1978, 1980a; Haggbloom \& Tillman, 1980) or within S+ (Haggbloom, 1980a, $1980 \mathrm{~b}, 1980 \mathrm{c}, 1981 \mathrm{~b}$ ) during discrimination learning. This effect of N-R transitions on resistance to discrimination closely parallels the effect of N-R transitions on resistance to extinction following conventional PRF (e.g., Capaldi, 1966).

The finding here that discrimination learning was facilitated by a +- sequence relative to $a+-+$ sequence is also in agreement with previous results (Haggbloom, 1978; Haggbloom \& Tillman, 1980). It is especially noteworthy that the effects of pretraining reward schedule were independent of discrimination trial sequence. According to an extension of Capaldi's (1966) sequential theory to discrimination learning (e.g., Haggbloom, 1978; Haggbloom \& Tillman, 1980), the effects of $N-R$ transitions on resistance to discrimination are mediated by the behavioral control acquired by $\mathrm{S}^{\mathrm{N}}$. During pretraining in the present experiment, $S^{N}$ would have acquired the capacity to elicit responding, which is acquired on $\mathrm{N}-\mathrm{R}$ transitions, only in Group NR. In groups given the +- sequence during the discrimination phase, $\mathrm{S}^{\mathrm{N}}$ occasioned in $\mathrm{S}-$ on Trials 4 and 5 each day, would be recalled on Trials 5 and 6 . In Group NR, $\mathrm{S}^{\mathrm{N}}$ in compound with $\mathrm{S}$ - would elicit faster running than would have been elicited by $S$ - alone because of the habit strength acquired by $\mathbf{S}^{\mathrm{N}}$ on N-R transitions during pretraining. In Groups RN, CRF, and $\mathrm{NP}$, on the other hand, $\mathrm{S}^{\mathrm{N}}$ would function merely as an additional $\mathrm{S}$ - cue, thereby facilitating discrimination learning.

In order for like effects of pretraining schedule to occur in the +-+ sequence condition during discrimination learning, it is necessary for $\mathrm{S}-$ to serve as a retrieval cue for the memory $\mathrm{S}^{\mathrm{N}}$, as has been suggested by Capaldi (1971) and Haggbloom (1980a, $1980 \mathrm{~b}$ ). Consider the sequence $\mathrm{S}+\mathrm{S}-\mathrm{S}+\mathrm{S}-\mathrm{S}+\mathrm{S}-$, one of the three used here. In order for $S^{N}$ to elicit fast running in $\mathrm{S}$ - in Group NR under this discrimination trial sequence condition, $\mathrm{S}^{\mathrm{N}}$ occasioned on Trial 2 must be retrieved in $S-$ on Trial 4 rather than on $S+$ on Trial 3. Similarly, $\mathbf{S}^{N}$ occasioned on 
Trial 4 must be retrieved in $S-$ on Trial 6 rather than in S+ on Trial 5.

One difficulty with this view is that the poorer discriminative behavior obtained here and previously under +-+ discrimination trial sequence conditions has been attributed to the behavioral control acquired by $S^{N}$ on transitions from $S-$ to $S+$ (Haggbloom, 1978; Haggbloom \& Tillman, 1980). In other words, $\mathrm{S}^{\mathbf{N}}$ occasioned in $\mathrm{S}-$ must be retrieved on a subsequent trial in $\mathrm{S}+$ to gain control over behavior under $\mathrm{a}+-+$ sequence.

The problem can be resolved by assuming, as suggested elsewhere (Haggbloom, 1980a, 1980b), that, in the early trials of differential conditioning, $\mathrm{SN}^{\mathrm{N}}$ occasioned in $\mathrm{S}-$ is retrieved on the immediately subsequent trial, whether that trial is in $\mathrm{S}-$ or $\mathrm{S}+$; but, as $\mathbf{S}$ - and $\mathbf{S}+$ come to be responded to as signals for differential reward outcomes, they also come to serve as cues for the retrieval of reward-related memories such as $\mathrm{S}^{\mathbf{N}}$ so that, later in discrimination learning, $\mathrm{S}^{\mathrm{N}}$ occasioned in $\mathrm{S}-$ would be retrieved only on a subsequent $S$ - trial even though trials to $S+$ may intervene. This hypothesis allows like effects of pretraining schedule on resistance to discrimination to be predicted for both +- and +-+ discrimination trial sequences, as well as retarded discrimination learning under +-+ relative to +- sequences. Consistent with this hypothesis, Haggbloom (1980a) reported that $\mathrm{N}-\mathrm{R}$ transitions within $\mathrm{S}+$ and from $S$ - to $S+$ provided from the outset of training had equal effects on resistance to discrimination, whereas, if no N-R transitions of either type occurred until after the discrimination was formed, only N-R transitions within $S+$ increased resistance to discrimination. N-R transitions from $S-$ to $S+$ introduced late in discrimination training did not effectively condition responding to $\mathrm{S}^{\mathrm{N}}$.

As a final point, Hall (1976) cited Galbraith's (1973) finding that PRF pretraining retards discrimination learning as support for the view that rats learn to ignore stimuli that are uncorrelated with reward outcome (learned irrelevance). While I have obtained results consistent with this view in a CRF pretraining condition in a blocking design (Haggbloom, 1981a), pretraining experiments as a whole appear equivocal on this point. Here, PRF pretraining retarded discrimination learning only in a group given $N-R$ transitions, but brightness was equally irrelevant in Group RN. Furthermore, it is not clear why CRF pretraining administered to both discriminanda would not result in the same degree of learned irrelevance as PRF pretraining. In fact, though, CRF pretraining either facilitates discrimination learning (Amsel \& Ward, 1965; Galbraith, 1973) or has little or no effect (Mandler \& Goldberg, 1973; and the present experiment) relative to a nonpretrained control group.

\section{REFERENCES}

AMsel, A., \& WARD, J. S. Frustration and persistence: Resistance to discrimination following prior experience with the discriminanda. Psychological Monographs, 1965, 79(Whole No. 597).

Capaldi, E. J. Partial reinforcement: An hypothesis of sequential effects. Psychological Review, 1966, 73, 459-477.

CAPAldi, E. J. Memory and learning: A sequential viewpoint. In W. Honig \& P. H. R. James (Eds.), Animal memory. New York: Academic Press, 1971.

Capaldi, E. J., Berg, R. F., \& Morris, M. D. Stimulus control of responding in the early trials of differential conditioning. Learning and Motivation, 1975, 6, 217-229.

GALBRAITH, K. Fractional anticipatory goal responses as cues in discrimination learning. Journal of Experimental Psychology, $1973,97,177-181$

HAGgBLOOM, S. J. Intertrial interval effects on internal stimulus control of behavior in brightness differential conditioning. Learning and Motivation, 1978, 9, 347-358.

HAGgBLoOM, S. J. Effects of training level and locus of N-R transitions on resistance to discrimination. Psychological Record, $1980,30,419-422$. (a)

Haggbloom, S. J. Resistance to discrimination and subsequent resistance to extinction as a function of the sequence of partial S+ reward in differential conditioning. Animal Learning \& Behavior, 1980, 8, 441-446. (b)

HaGgBloom, S. J. Reward sequence and reinforcement level as determinants of $\mathrm{S}-$ behavior in differential conditioning. Animal Learning \& Behavior, 1980, 8, 424-428. (c)

HAGGBLOOM, S. J. Blocking in successive differential conditioning: Prior acquisition of control by internal cues blocks the acquisition of control by brightness. Learning and Motivation, 1981, 12, 485-508. (a)

HaGgBLoom, S. J. Effects of reinforcement level and number of N-R transitions on resistance to discrimination. Bulletin of the Psychonomic Society, 1981, 17, 197-199. (b)

Haggbloom, S. J., \& Tillman, D. J. Sequential effects on discrimination reversal. Learning and Motivation, 1980, 11, 318-338.

HALL, G. Learning to ignore irrelevant stimuli: Variations within and between displays. Quarterly Journal of Experimental Psychology, 1976, 28, 247-253.

Mandlen, J. M., \& Goldberg, J. Effects of partially and continuously reinforced pretraining on choice and latency measures in the rat. Journal of Comparative and Physiological Psychology, $1973,84,118-127$.

McHose, J. H., \& Blackwell, D. R. Performance in differential instrumental conditioning as a function of the pattern of partial S+ reward. Animal Learning \& Behavior, 1975, 3, 63-66.

Purdy, J. E., \& Cross, H. A. The role of $R-S^{*}$ expectancy in discrimination and discrimination reversal learning. Learning and Motivation, 1979, 10, 211-227.

(Manuscript received July 28, 1981;

revision accepted for publication September 22, 1981.) 